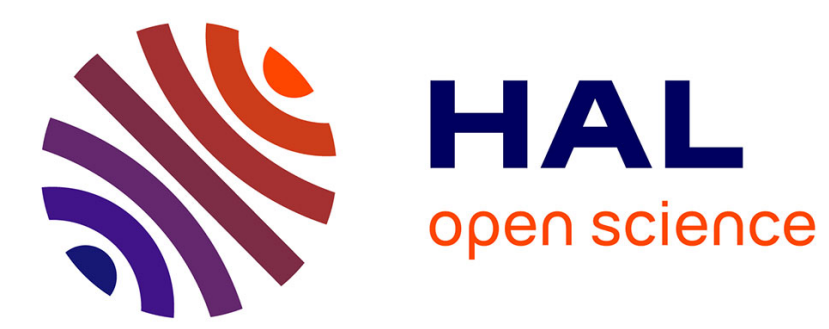

\title{
SOME UNRESOLVED ISSUES IN PHASE TRANSFORMATIONS - THE ROLE OF MICROANALYSIS
}

H. Bhadeshia

\section{- To cite this version:}

H. Bhadeshia. SOME UNRESOLVED ISSUES IN PHASE TRANSFORMATIONS - THE ROLE OF MICROANALYSIS. Journal de Physique Colloques, 1989, 50 (C8), pp.C8-389-C8-394. 10.1051/jphyscol:1989866 . jpa-00229964

\section{HAL Id: jpa-00229964 https://hal.science/jpa-00229964}

Submitted on 1 Jan 1989

HAL is a multi-disciplinary open access archive for the deposit and dissemination of scientific research documents, whether they are published or not. The documents may come from teaching and research institutions in France or abroad, or from public or private research centers.
L'archive ouverte pluridisciplinaire HAL, est destinée au dépôt et à la diffusion de documents scientifiques de niveau recherche, publiés ou non, émanant des établissements d'enseignement et de recherche français ou étrangers, des laboratoires publics ou privés. 


\section{H. K. D.H. BHADESHIA}

University of Cambridge, Department of Materials Science and Metallurgy, Pembroke street, GB-Cambridge CB2 3QZ, Great-Britain

Abstract - A few of the current difficulties associated with first order phase transformations are reviewed in the context of the facilities offered by fine scale microanalytical techniques. The aim is to stimulate cooperation between those who are experts in field ion microscopy and associated techniques, and others involved in the modelling of phase transformations and microstructures.

\section{1 - INTRODUCTION}

There has been remarkable progress in the past thirty years or so, in the use of experimental thermodynamic data combined with clever methods of solving complicated systems of nonlinear equations, towards the calculation of phase diagrams for metals and alloys /1/. There are now several systems capable of estimating the phase diagram as a function of pressure, temperature and the combined effect of numerous alloying elements, given a starting set of possible phases $/ 1 /$. Since the thermodynamic properties of a metastable phase are continuous with its properties under equilibrium conditions, the calculations can be used to extrapolate the phase boundaries into regimes where the phases are not thermodynamically stable. This is an important facility, since kinetic barriers in reality often allow a phase to exist happily even though it may be unstable.

Phase diagrams per se are of considerable value in the design of alloys $/ 1,2 /$, but in many applications, kinetic considerations are of overriding importance and control the development of microstructure, and hence the properties, of metals. Consequently, the next major advance in the theory of materials is likely to be in the development of kinetic models, which enable the estimation of microstructure as a function of chemistry and thermomechanical treatments. Of course, kinetic theory itself is already well advanced $/ 3 /$, but it often relies on assumptions such as the existence of local equilibrium at the interface, which may not be realistic when considering transformations at high supersaturations /4/. Many large scale industrial processes are now tending towards conditions of high supercooling, since it is in those circumstances that ultrafine grained microstructures, phases with nonequilibrium solute concentrations, etc. can be produced $/ 5 /$.

The purpose of this review is to identify a small number of problems related to the modelling of microstructure, which could in principle benefit from carefully designed microanalysis experiments. Metals, and in particular steels, are probably the best disposed of all materials to benefit from developments in kinetic theory, since metallurgy is a relatively advanced science, with a large experimental database. Such a database is necessary to allow discrimination between different theories. For this reason, and because of the author's personal interests, the review focuses on metals, although it will become evident that the problems and solutions are of general applicability.

\section{2 - EQUILIBRIUM TO PARAEQUILIBRIUM TRANSITION}

As pointed out earlier; it is a common assumption that local equilibrium exists at the transformation during diffusion controlled growth. For binary alloys, this means that the compositions $x^{\alpha \gamma}$ and $x^{\gamma \alpha}$ of the product $(\alpha)$ and parent $(\gamma)$ phases respectively, at the interface, are specified by a tie-line of the $(\alpha+\gamma)$ two-phase field of the phase diagram; see for example, $/ 3,6 /$. Conservation of mass then requires that the amount of solute being partitioned between the phases per unit of time is balanced by the solute diffusion flux at the interface:

$$
\left(x^{\alpha \gamma}-x^{\gamma \alpha}\right) v=D(\partial x / \partial z)
$$

where $D$ is the solute diffusivity, $v$ is the interfacial velocity and $z$ the coordinate normal to the interface. Note that the concentration gradient is evaluated in the parent phase at the interface. 
For the local equilibrium assumption to be viable, there must exist sufficient atomic mobility at the transformation temperature. In an alloy in which there is some atomic mobility within the parent phase, the reconstruction of the crystal structure may provide an opportunity for the solvent and solute atoms to redistribute between the two phases. However, in a system such as Fe-C-X (where X represents a substitutional solute), the diffusion rate of carbon in the austenite may be many orders of magnitude greater than that of a substitutional atom in the temperature range of interest and these very different rates of atomic migration mean that true equilibrium segregation with regard to all components may not be produced at a migrating interface. If the interaction between the fluxes of the two species is neglected, then in terms of the mass conservation conditions, there are two equations to be satisfied simultaneously:

$$
\begin{aligned}
& \left(x_{1}^{\alpha \gamma}-x_{1}^{\gamma \alpha}\right) v=D_{1}\left(\partial x_{1} / \partial z\right) \\
& \left(x_{2}^{\alpha \gamma}-x_{2}^{\gamma \alpha}\right) v=D_{2}\left(\partial x_{2} / \partial z\right)
\end{aligned}
$$

where the subscripts 1 and 2 identify the interstitial and substitutional solute species respectively. Since the diffusivities differ by many orders of magnitude, simultaneous solution is in general impossible for the case where the tie-line passes through the average composition of the alloy concerned.

It is, however, possible to envisage growth under diffusion control with local equilibrium at the interface in the sense that the compositions of the two phases are joined by a tie line of the equilibrium diagram, even though this tie line does not pass through the point representing the initial (or average) composition of the alloy. When these kinetic restrictions apply, the two phases may differ either significantly or negligibly in substitutional solute content. A qualitative analysis for ternary steels was first developed by Hillert $/ 7 /$, and a simplified quantitative theory in which diffusion cross terms are neglected was developed by Kirkaldy $/ 8 /$, Purdy et al. $/ 9 /$, and Coates $/ 10 /$; the effect of the cross terms was later examined by Coates $/ 11,12 /$. The simple theory shows that for the diffusion-controlled growth of ferrite from austenite in an $\mathrm{Fe}-\mathrm{C}-\mathrm{X}$ alloy with initial composition near the $\gamma /(\gamma+\alpha)$ phase boundary (i.e. with a small supersaturation), the tie line selected will have the carbon composition of the austenite at the interface almost equal to that of the bulk alloy so that the activity of carbon is nearly constant in the austenite, thus reducing the driving force for carbon diffusion almost to zero. There will be a concentration gradient of the substitutional solute ahead of the interface, resulting in appreciable partition, and the relatively slow growth rate will be determined by the diffusion rate of this solute. For large supersaturations, the tie line will have the $\mathrm{Fe}+\mathrm{X}$ composition of the ferrite virtually identical with that of the bulk austenite, partitioning of the substitutional solute will be extremely small, with a relatively fast growth rate. These are, referred to as the partitioning local equilibrium (P-LE) and negligible partitioning local equilibrium (NP-LE) growth modes respectively $/ 9,12,5 /$, and for a high ratio of the diffusivities, the theory predicts an abrupt transition from one to the other as the supersaturation increases.

In the NP-LE mode, the concentration of $\mathrm{X}$ is uniform except for a small "spike" in the parent phase adjacent to the interface. As the ratio of interstitial: substitutional diffusion rates increases, the width of this spike decreases, and when it becomes of the order of atomic dimensions, the concept of local equilibrium at the interface is invalid and has to be replaced (assuming the growth is nevertheless diffusion-controlled) by that of paraequilibrium $/ 13-17 /$. In conditions of paraequilibrium, there is no redistribution of $\mathrm{Fe}+\mathrm{X}$ atoms between the phases, the $\mathrm{Fe} / \mathrm{X}$ ratio remaining uniform right up to the interface. One interpretation of the paraequilibrium limit is that reconstructive transformation occurs with all displacements of the $\mathrm{Fe}+\mathrm{X}$ atoms taking place in the incoherent interface; another interpretation might be that only displacive transformation can occur. In either case, to quote from Coates, "the slow diffuser and the solvent participate only in the change of crystal structure". Paraequilibrium implies that the growth rate is controlled by the interstitial diffusivity, the interface compositions now being given by the tie lines of the pseudo-equilibrium between the two phases under the constraint of a constant Fe-X ratio.

\section{3 - TASK NUMBER ONE}

To summarise the discussion, when Fe-C-X alloys are transformed at low supersaturations, there is bulk partitioning of the slow diffuser, the activity gradient of the fast diffuser being reduced to a negligible level (the P-LE mode, Fig. 1). At high supersaturations, there is negligible partitioning of the slow diffuser, so that its activity gradient in the parent phase is large enough to allow it to keep pace with the faster diffusing element. Paraequilibrium transformation involves zero partitioning of substitutional elements 


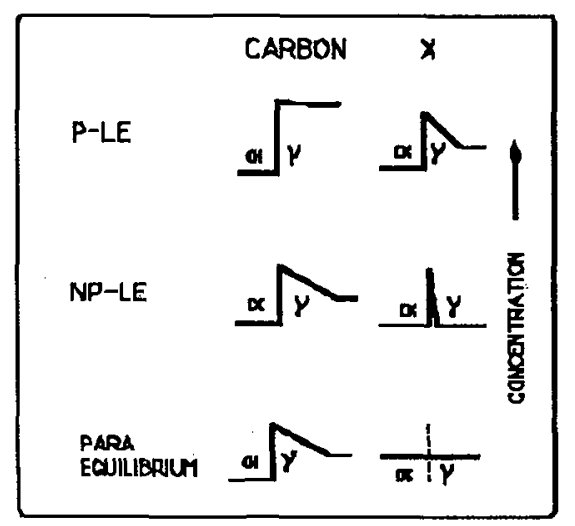

Fig. 1 -Diagrams illustrating the concentration profiles at the transformation interfaces, for the P-LE, NP-LE, and paraequilibrium modes.

during transformation, the ratio of substitutional solute to iron atoms being constant everywhere, even on the finest conceivable scale.

There is as yet no complete theory for the transition from local equilibrium to paraequilibrium. The conjecture $/ 12,18 /$ that the transition occurs when the calculated extent of the diffusion field of the slow diffuser becomes comparable to atomic dimensions is unlikely to be correct, because the calculations do not included gradient energy terms $/ 12,6 /$. There is also evidence that the kinetics of some transformations are compatible with local equilibrium even when the extent of the calculated diffusion field is negligible $/ 19 /$.

The task for the microanalysis expert is clear: there is a need to examine the concentration profiles at the transformation interfaces, firstly to establish the local equilibrium assumption for ternary alloys, and secondly to provide direct experimental data on the conditions under which local equilibrium gives way to paraequilibrium. It may even be the case that the paraequilibrium condition does not exist when the mechanism of transformation is reconstructive. It is also likely that there may be an infinite set of intermediate conditions between the limiting cases of local and paraequilibrium $/ 6 /$.

\section{4 - MECHANISM OF TRANSFORMATION}

The behaviour of the atoms on substitutional sites during transformation is critical in specifying the mechanism of change.

In a displacive transformation (Fig. 2), the pattern in which the substitutional atoms are arranged changes in a manner consistent with the change in crystal structure; since the change does not involve any diffusion of these atoms, the shape of the whole crystal changes. This shape deformation has the exact characteristics of an invariant-plane strain with a relatively large shear component. Interstitial atoms may diffuse during transformation without influencing the observed shape deformation $/ 20 /$. There is however, no significant diffusion of substitutional atoms in a displacive reaction.

During reconstructive transformation (Fig. 2), the atoms transfer across the interface in an uncoordinated manner which accomplishes the required lattice change and simultaneously ensures a minimisation of the strain energy. This requires the thermally activated migration (in the interface region at least) of all the atoms, irrespective of whether the transformation occurs in a pure metal or in an alloy. There will normally be a volume change associated with the stress-free change of structure, and at sufficiently high temperatures, this may be compensated by a flux of vacancies (and an opposite flux of atoms) between the growing precipitate and the dislocations, grain boundaries and (ultimately) the free surface of the parent phase. At temperatures where the rate of diffusion in the parent phase is inadequate for such an adjustment, reconstructive growth with minimum strain energy will still be possible if the precipitate has a lenticular (tapered plate) shape, and the reconstruction takes place in such a way that the volume change is simply an expansion or contraction normal to the plane of the lens $/ 21 /$. This can be achieved by atomic migration entirely within, or in the limit, around the particle. Reconstructive growth 
DISPLACIVE

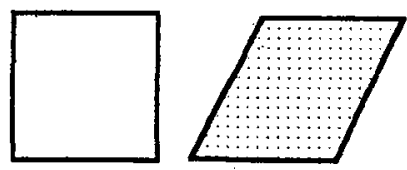

RECONSTRUCTIVE
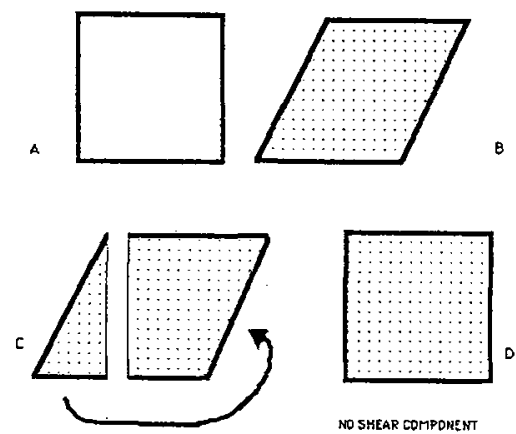

Fig. 2 -Illustration of the mechanisms of transformation. For a displacive transformation, the change in crystal structure is accomplished by a physical deformation. For a reconstructive reaction, there is an additional phenomenological step, which involves mass transport (reconstructive diffusion) and which ensures a minimum of strain energy.

is, however, scarcely feasible unless all atoms have some mobility in the incoherent interface, roughly equivalent during the time of growth to a diffusion distance of the order of the order of magnitude of the dimensions of the particle. This necessary mass flow has been described as "reconstructive diffusion" $/ 6 /$.

\section{5 - TASK NUMBER TWO}

The above discussion emphasises the difference in the displacive and reconstructive of transformation, even when the metal concerned in pure. Apart from academic interest, such differences are of vital importance in the modelling of phase transformations. The nature of the shape deformation clearly can help identify the mode of transformation, but the product phase particles may be too small for the deformation to be characterised. This is the case for carbide precipitation during the tempering of martensite, or during bainitic transformations, where it has often been proposed, that the carbides grow by a paraequilibrium, displacive transformation mechanism.

The substitutional solute content of the product phase can also be monitored, but bulk measurements do not give conclusive data, since reconstructive transformation can sometimes occur without bulk partitioning. Very fine scale microanalysis with atomic resolution can however be used, to establish either local partitioning, or segregation into the transformation interface; both of these phenomena would be inconsistent with a displacive transformation mechanism.

An interesting approach in circumstances where the shape deformation cannot easily be established, could involve the monitoring of any reconstructive diffusion during transformation. Such diffusion would be invisible in a pure metal, but not so for an alloy which tends to precipitate other phases as a consequence of heat treatment. Stark and Smith have published data on the size of molybdenum carbide particles obtained during the formation of ferrite from austenite /22/. An analysis of their data is presented in Fig: 3. It indicates clearly the absence of any molybdenum carbide as the formation of ferrite by reconstructive transformation gives way to the displacive growth of bainitic ferrite. It is apparent that atomic mobility at the temperatures where bainitic ferrite forms can be incredibly small $(<1 \mathrm{~nm}$ for the data discussed). 


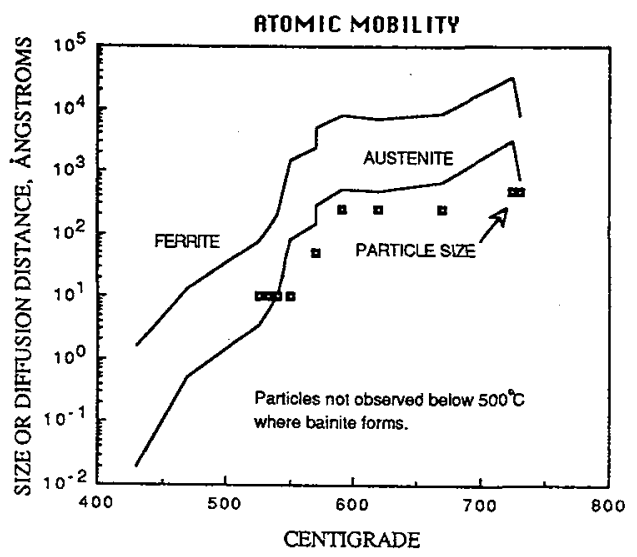

Fig. 3-Analysis indicating the degree of atomic mobility available in Fe-Mo-C alloys (the data illustrated as points are due to Stark and Smith $/ 22 /$ ). The lines represent a $2 D^{0.5} t^{0.5}$ random walk distance for Mo in austenite and ferrite, for all of the transformation conditions used, including cases where no carbides could be detected during the formation of ferrite $\left(T<500^{\circ} \mathrm{C}\right)$.

\section{6 - CARBIDES: TIIE APPROACH TO EQUILIBRIUM}

It has long been established that the cementite associated with bainite has a substitutional alloy content which is similar to the average concentration of the steel concerned $/ 21,23 /$. The way in which the composition of this cementite changes during tempering, has assumed new significance in recent years. In the power generation industry, creep resistant bainitic steels are in service at elevated temperatures for many years. It is then important, for safety reasons, to know accurately the time-temperature history of the steel at any stage during service. This determines the amount of creep life remaining (i.e. the remancnt life). It has been proposed that the composition of cementite, monitored using non-destructive microanalytical techniques, can be used as a built in recorder for the time-temperature cycle experienced by the steel $/ 24,25 /$.

\section{7 - TASK NUMBER TIIREE}

Theoretical modelling / $26 /$ of the enrichment kinetics of cementite indicates that due to the large disparity in the equilibrium chromium concentrations of cementite and ferrite at the temperatures of interest, it is unlikely that the composition of the cementite at the interface is anywhere near equilibrium during much of the enrichment process. This, and other predictions about the nature of the concentration profiles that develop in the vicinity need verification using high resolution microanalysis. During the later stages of ageing, alloy carbides must precipitate at the expense of cementite, and the consequential modification of diffusion fields, together with the virgin (probably nonequilibrium) compositions of the alloy carbides needs quantitative characterisation.

\section{8 - SOLUTE DRAG}

This is a very controversial area $/ 6 /$, which probably can only be resolved using high resolution microanalysis techniques. Neither the theory, nor the experimental data for solute drag at transformation interfaces are convincing. When a transformation interface moves, the available driving force may be dissipated in a series of processes, including the diffusion of solute ahead of the interface, the transfer of atoms across the interface, and in the diffusion of solute atoms which have segregated to the interface. It is this latter segregation which is the origin of solute drag, but a common, yet incorrect, assumption is that the segregation in itself constitutes sufficient evidence for the existence of drag. It is only if free energy is dissipated in diffusion of the segregated solute, as the interface moves, that drag arises. In physical terms, this means that the concentration of segregated solute must be nonuniform as a function of distance normal to the interface, as the interface moves. In modelling solute drag, some authors allow 
the segregate distribution to be nonuniform within the interface, although that concept seems dubious given that the width of an interface is likely to be atomic dimensions. A more realistic proposition, by analogy with well established theory for solute drag at grain boundaries $/ 27 /$, is that for a moving interface, the concentration profile of the segregate is likely to extend outside of the interface itself.

\section{9 - $\underline{\text { TASK NUMBER FOUR }}$}

Careful measurements of the concentration profiles at the transformation interface should convincingly demonstrate the presence or absence of drag effects, and provide a good database for the development of solute drag theory. The profiles should be measured at the position of the interface, and in the parent and product phases in the vicinity of the interface. It is emphasised again, that the observation of segregation in itself does not demonstrate solute drag, but rather, the observation of nonuniformity in segregate concentration in either direction normal to the plane of the interface. Experiments to detect such effects are long overdue, and are probably best carried out on alloys undergoing massive transformations, since interference with diffusion fields due to partitioning between phases can then be avoided.

10 - AGKNOWLEDGEMENTS The author is grateful to the Organising Committee for the opportunity to air some ideas, and to Professor D. Hull for the provision of laboratory facilities at the University of Cambridge.

\section{REPERENCES}

/1/ Doane, D. V. and Kirkaldy, J. S., (eds.), "Hardenability Concepts with Applications to Steels", TMS-AIME, Warrendale, Pennsylvania, (1978).

/2/ Azad, A. M., Stesdharan, O. M. and Rodriguez, P., J. of Alloy Phase Diagrams $\mathbf{5}$ (1989) 1.

/3/ Christian, J. W., "Theory of Transformations in Metals and Alloys", 2nd ed., Part I, Pergamon Press, Oxford (1975).

/4/ Turnbull, D., Metall. Trans. A 12A (1981) 695.

/5/ Bhadeshia, H. K. D. H., Steel Technology International (1989).

/6/ Bhadeshia, H. K. D. Ir., Progress in Materials Science 29 (1985) 321.

/7/ IIillert, M., Internal Report, Swedish Inst. Met. Res. (1953).

/8/ Kirkaldy, J. S., Can. J. Phys. $\underline{36}$ (1958) 907.

/9/ Purdy, G. R., Weichert, D. II. and Kirkaldy, J. S., Trans. Met. Soc. AIME 230 (1964) 1025.

/10/ Coates, D. E., Metall. Trans. $\underline{3}$ (1972) 1203.

/11/ Coates, D. E., Metall. Trans. 4 (1973) 1077.

/12/ Coates, D. E., Metall. Trans. 4 (1973) 2313.

/13/ IJultgren, A., Jernkontorets Ann. 135 (1951) 403.

114/ Rudberg, E., Jernkontorets Ann. $\underline{136}$ (1952) 91.

/15/ IIillert, M., Jernkontorets Ann. $\underline{136}$ (1952) 25.

/16/ Aaronson, H. I., Domian, H. A. and Pound, G. M., Trans. Met. Soc. AIME 236 (1966) 753.

/17/ Aaronson, HI. I., Domian, H. A. and Pound, G. M., Trans. Met. Soc. AIME 236 (1966) 768.

18/ IIillert, M., "Mechanism of Phase Transformations in Crystalline Solids", Institute of Metals, London (1969) 231.

19/ Hillert, M., "Solid-Solid Phase Transformations", TMS-AIME, Warrendale, Pennsylvania (1981) 789.

/20/ Christian, J. W., "Physical Properties of Martensite and Bainite", Spec. Rep. 93, Iron and Steel Inst., London (1965) 1.

/21/ Bhadeshia, H. K. D. H. and Christian, J. W., Metall. Trans. A, (1989), in press.

/22/ Stark, 1., D.Sc. Thesis, University of Oxford (1988).

123/ Chance, J. and Ridley, N., Metall. Trans. 12A (1981) 1205.

/24/ Carruthers, R. B. and Collins, M. J., "Quantitative Microanalysis with IIigh Spatial Resolution", Institute of Metals, London (1981) 108.

/25/ $\Lambda$ frouz, A., Collins, M. J. and Pilkington, R., Metals Tech. 10 (1983) 461.

/26/ Bhadeshia, H. K. D. H., Materials Science and Technology $\underline{5}$ (1989) 131.

/27/ Caln, J. W., Acta Metall. 10 (1962) 789. 